\title{
COVID-19 in occupational settings: lessons from 100 years ago and addressing the disease today
}

\section{Bobby Joseph ${ }^{1}$, Mia George Kallumkal ${ }^{2}$}

${ }^{1}$ Professor, Community Health and Head, Occupational Health Services, Department of Community Health, St. John's Medical College, Bangalore 560034; ${ }^{2}$ Tutor, Community Health, Department of Community Health, St. John's Medical College, Bangalore 560034

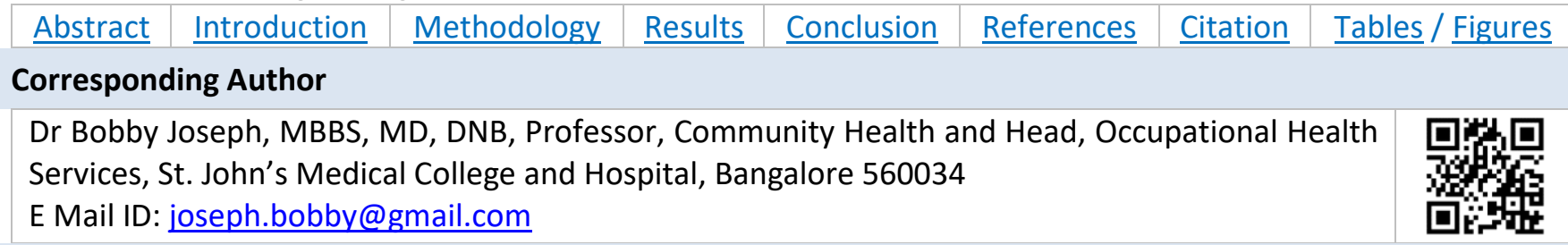

\section{Citation}

Joseph B, Kallumkal MG. COVID-19 in occupational settings: lessons from 100 years ago and addressing the disease today. Indian J Comm Health. 2020;32(2-Special Issue):255-260.

Source of Funding: Nil Conflict of Interest: None declared

\section{Article Cycle}

Received: 13/04/2020; Revision: 15/04/2020; Accepted: 16/04/2020; Published: 20/04/2020

This work is licensed under a Creative Commons Attribution 4.0 International License.

\section{Abstract}

COVID-19 is a disease caused by the novel coronavirus (SARS-CoV-2). On January 30th, 2020 the outbreak of Novel Coronavirus 2019 was declared a Public Health Emergency of International Concern by the World Health Organization. COVID-19 was declared a pandemic on the 11th of March 2020. The virus spreads from person to person through close contact, touching contaminated surfaces and then touching the eyes, nose or mouth. Preventive measures are taken at all workplaces to stop the spread of COVID-19. Social distancing, regular hand washing with soap and water for 20 seconds, use of alcohol- based hand sanitizer and cough etiquette must be practiced at all times. Hospitals, schools, colleges, hospitality, apparel and manufacturing industries now practice hand hygiene, social distancing, regular disinfection of contaminated surfaces, staggered work shifts, correct use of face mask if mild symptoms develop and shutting down of establishments as per instructions of the local health authorities. COVID-19 is already affecting tens of millions of informal workers all around the world. India has a share of almost 90 percent of working people which amount to 400 million workers in the informal economy, who are at the risk of falling into poverty during this crisis. The current lock down measures in India have affected these workers, compelling them to return to rural areas. Poverty along with the spread of the COVID-19 would further worsen the situation. Without dwelling on the healthcare setting, this paper discusses various preventive measures to be implemented in three different sectors. These interventions can be adapted to others as well, to stop the transmission of COVID-19.

\section{Keywords}

COVID-19; Occupational Settings; Pandemic; Prevention

Two months ago, on the mid-afternoon of January 30th, 2020 the outbreak of Novel Coronavirus 2019 was declared a Public Health Emergency of International Concern at Geneva by the Emergency Committee convened by the World Health Organization (WHO) Director General(1). A month later WHO announced a new name for the novel coronavirus disease: COVID-19. At the end of
February 2020, COVID-19 was considered to have a pandemic potential(1). The last time the world heard the term 'Pandemic' was way back in 1918 and then in 2009. On the 11th of March, 2020 COVID-19 was characterized as a pandemic(1).

Pandemics in the Past and Lessons Learnt

We have seen a total of 20 pandemics since 165 A.D, including the flu pandemics. The Influenza Pandemic 
in 1918 followed by the H1N1 Influenza Pandemic in 2009 were some of the deadly flu pandemics the world dealt with. Influenza Pandemic of 1918 showcased the scope of the public health system to grow as one of the best defenses against the pandemic(2). How different pandemics target different groups in a population was another lesson the previous flu pandemic taught the world(2). The idea of treating case-by-case will not be enough during a pandemic, was also learnt(2). The flu pandemics of the past brought out several possible interventions to mitigate the effects of an influenza pandemic in the future(3).

\section{Lessons from the 1918 - 1919 Influenza Pandemic}

The Spanish Flu has been described as the "greatest medical holocaust in history"(2). It claimed lives of $3 \%$ of the world's population. This pandemic flared up twice before dying down the subsequent year(4). However, this pandemic is incorrectly dubbed as 'Spanish flu'(5). The press in Spain was free to talk about the crippling effects of the pandemic as Spain was one of the countries that remained neutral in the First World War. Thus, Spain was generally perceived as the place of origin of this pandemic(5).Notification of suspected cases were made mandatory followed by voluntary or mandatory quarantine. Communities like schools, boarding schools and barracks were under surveillance. Public meeting platforms/places were closed followed by abeyance of public gatherings. Number of passengers in a public transport was limited. People were banned from crowding outside the shops. Streets were disinfected regularly. Cleaning and disinfection of public spaces like churches, cinema halls, theatres and workshops were carried out regularly. Free soap and clean water were made available to the poor. Spitting in the street was prohibited(5). Legislation was called for to prevent use of common cups(6). Laws were enforced to practice social distancing and cough etiquette. Institutional quarantine was enforced in military training camps (6). Mortuary police services were simplified by setting up collection points for corpses and rituals associated with death were abolished. The general public was directed to wear the masks and given clear instructions on correct use of the mask. Public was instructed to avoid wearing a mask used by another individual. The mask once removed was to be folded with the inside folded in, followed by immediate boiling (for ten minutes) and disinfection(6).
How do we make our workplaces COVID-19 ready?

Amidst the pandemic the World Health Organization along with the public health authorities around the world have laid down measures to stop the spread of COVID-19 in the workplace. Surfaces and objects have to be disinfected regularly. Hand sanitizers and hand rub dispensers must be placed at prominent places in the work area. Timely refilling of the dispensers must be ensured. Posters promoting handwashing practices as per the WHO guidelines must be displayed. Availability of paper napkins and face masks for employees who develop symptoms of upper respiratory tract infections must be ensured. Closed bins for the disposal of used paper napkins and face masks must be made available around the clock. Employees must be advised to consult the national travel advice before going on business trips. Employees must be briefed on certain specific topics including the symptoms of COVID-19, the mode of transmission and the importance of staying home even in case of developing mild symptoms. The necessity of meetings and events scheduled must be reassessed. If the face to face meetings are inevitable and cannot be replaced by a teleconference or an online event the following precautions must be followed(7). In today's business and corporate atmosphere, the following steps are important:

- Advice from the authorities in the community must be sought and enforced

- Scaling down the event such that lesser number of individuals attend the meeting

- Public health and health care authorities must be informed, and communication channels must be maintained

- Contact details of all the participants of the meeting must be collected, verified and retained

- Availability of hand sanitizers for all the participants and surgical masks for participants who have mild symptoms must be ensured

- Practice of cough etiquette must be reinforced

- Refrain from shaking hands

- Use of alcohol-based hand rub and handwashing with soap and water must be practiced during the meeting

- Health hotline number must be provided to all the participants

- A seating arrangement that provides a six-foot gap between each participant must be set up

- The venue must be well ventilated 
- If a participant at the meeting or event was isolated as a suspected COVID-19 case, the organizer should inform all the participants. The participants must be advised to monitor themselves for symptoms for 14 days and measure their body temperature twice a day(7). In any event of employees returning from an international trip, they must be advised to monitor themselves for 14 days along with measuring the body temperature twice a day. If the employee develops symptoms they must be instructed to selfisolate and get in touch with their healthcare provider or local public health department over the telephone(7) (104 - medical helpline in India).

\section{Preventive Measures in Selected Sectors}

Centre For Disease Control and Prevention (CDC) has issued guidelines to stop the spread of COVID-19, which have to followed at all times. The general preventive measures applicable to all sectors included in the guidelines(8) are as follows:

- Hand wash - Hands must be washed with soap and water for at least 20 seconds specially after coughing, sneezing, blowing the nose and after being to a public place. Hand sanitizer containing $60 \%$ alcohol must be used if water and soap are not readily available. Avoid touching eyes and nose with unwashed hands.

- $\quad$ Staying home - stay home as much as possible. Close contact with people who are sick must be avoided. Grocery delivery and medication delivery must be considered.

- Social distancing - a distance of 6 feet must be kept between each other. All gatherings and meetings must be avoided. Public transport must be avoided

- Cloth mask - face cloth mask must be used to prevent spread of the infection to another person if one is infected. The cloth mask must be used when in a public place like a grocery shop or a supermarket. Cloth mask does not substitute social distancing. Face mask meant for the health personnel must not be used.

- Cough etiquette - the practice of coughing or sneezing into the tissue/elbow must be practiced. Used tissue must be disposed into the trash can. Hands must be washed with soap and water after coughing, sneezing and blowing the nose.

- Cleaning and disinfecting - frequently touched surfaces must be cleaned and disinfected daily. Frequently touched surfaces include tables, chairs, doorknobs, countertops, light switches, desks, faucets, sinks, toilets and phones.

Apart from these mandatory preventive measures CDC has issued guidelines regarding preventive measures to be followed at selected sectors(8).

While following the guidelines above, the discussion that follows looks at three different sectors. Lessons from these should be adapted to other work settings as well. The healthcare sector has been excluded from this discussion.

\section{Hospitality Industry}

Basic hygiene and safety advisories including regular hand washing with soap and water, practicing social distancing, practicing cough etiquette and wearing facemasks in case of development of mild symptoms should be enforced in various hotels and restaurants. Hotels and restaurants have been locked down but when they re-open they should conduct deep cleaning measures of restaurants, party/banquet halls and conference rooms(9).

Food security of most countries are largely not affected including e-commerce-based food/grocery delivery platforms(10). Importing of agro-chemicals including fertilizers are affected with the various import/export bans enforced globally(10). Farmers and agricultural workers must practice physical distancing, regular hand washing practices, use of cell phones for communication keeping social distancing in mind, to adhere to staggered meal breaks, to work according to split shifts and postpone non-essential work. They should be regularly spoken to about the importance of home quarantine and isolation in case of exposure to coronavirus infection. The symptoms of COVID-19 infection should be explained regularly at the work space(11).

The aviation sector being affected further results in a huge impact in the global tourism and hospitality sector. Travel bans put in place all over the world have resulted in less revenue generation in aviation sector(10). When these restrictions are removed, aircraft and cabin crew on commercial flights should follow the Airline guidelines set by Centers for Disease Control and Prevention (CDC). The preventive measure(12) to be taken are the following,

- The cabin crew should be trained to identify sick and potentially infectious passengers. 
- Preferably one cabin crew must be designated to attend to the sick patient and should seat the sick traveler at least $6 \mathrm{ft}$ away from the other passengers or move adjacent passengers without compromising the flight safety protocols so as to minimize the exposure.

- All the body fluids (loose stools, vomit or blood) must be treated infectious.

- Regular cleaning and disinfection of the contaminated areas should be made mandatory.

- Personal protective equipment must be used while tending to the patient.

- Waste disposable must be using the recommended procedures(12).

Apparel and other manufacturing sectors

The garment industry is a sector that employees a large population, globally and in India. This industry involves a sizeable amount of daily wage workers(13). A surge in the price of raw materials have affected the apparel/textile industry(13). The same situation is likely to be true in many other manufacturing sectors. The current situation being fluid, factories follow guidelines placed by the International Labour Organization and World Health Organization(13). The instructions included in the guidelines(13) are as follows:

- Factories involved in production of Personal Protective Equipment (PPE) and all other essential items must be exempted from any shutdown

- The symptoms of the coronavirus infection should be explained to the workers

- Importance of practicing social distancing must be explained to the workers

- Handwashing facilities should be installed in the factories

- Workers and employees should be instructed to wash their hands at regular intervals

- Breaks must be staggered

- Contaminated surfaces should be disinfected regularly

- Awareness sessions for the in-house doctors, welfare officers, safety committee members, management and workers themselves must be conducted.

\section{Educational Institutions}

Rising rates of sickness absenteeism of staff and students since the coronavirus outbreak were reported. Following which closure of schools was considered and enforced in many countries. Schools must remain closed as part of the community mitigation strategy $(14,15)$. Students and staff should remain home. Digital and distance learning must be planned and implemented. Importance of practicing regular hand washing and social distancing must be communicated to the students and staff. Ways to continue student services such as school meals must be planned and executed for students (and staff) remaining on campus. Local health department should be regularly consulted regarding the reopening of schools(14). While talking to children about the pandemic certain points have to be kept in mind. Some of them are as follows:

- Remain calm and reassure them

- Avoid language that might blame others. Also avoid stigmatization of a COVID-19 positive individual

- Pay attention to what the children hear and see on the television, radio and internet regarding COVID-19

- The information that one provides to the child must be honest and accurate(14)

Institutions for higher education should remain shut and must consult the local health department regarding re-opening. Administrators of these institutions must make sure that the cleaning staff regularly disinfects classrooms, bathrooms, hostels and other shared facilities. Student support services like online library services must continue to facilitate the continuity of research and education. Online classes must be scheduled. As in other settings, all non-critical gatherings and events must be cancelled. Students and staff must practice regular handwashing, social distancing, cough etiquette, correct use of face mask if the individual develops mild symptoms(16).

\section{Conclusion}

The flu pandemics of 1918 and 2009 have equipped the world to deal with similar situation fairly successfully(17). But the world has changed with increase in the number of factories, colleges, schools, hospitals, nursing homes and offices emerging all around the world(5). Travel across continents for work and leisure has increased $(2,18)$. However, as can be seen, even after 100 years the preventive steps taken to prevent the transmission of flu pandemics are not vastly different $(2,5)$.

India is home to 400 million workers in the informal economy, which amounts to a share of almost 90 percent of working people, who are at the risk of falling into poverty during this crisis(19). The current 
lockdown measures in India have affected these workers, compelling them to return to their hometowns in the rural areas. Our poverty-stricken population would further be impacted were COVID19 to spread in the community. The preventive measures, listed above and enforced in different work settings, must be adapted to individual workplaces to stop the transmission of COVID-19 among the working population and thereby preventing any impending catastrophe(19).

\section{Authors Contribution}

All authors have contributed equally.

\section{References}

1. who.int [internet]World Health Organization [cited 2020 Apr 13]. Available from: https://www.who.int/emergencies/diseases/novelcoronavirus-2019/events-as-they-happen

2. BBC Future[internet]British Broadcasting Corporation-Coronavirus-What can we learn from the Spanish Flu [cited 2020 Apr 13]. Available from: https://www.bbc.com/future/article/20200302coronavirus-what-can-we-learn-from-the-spanish-flu

3. Taubenberger JK, Morens DM. 19128 Infuenza: The Mother of All Pandemics. DOI: 10.3201/eid1201.050979 [Preprint]. [cited 2020 Apr 13]Available from: https://www.medigraphic.com/pdfs/revbio/bio2006/bio061i.pdf

4. Deemagclinic[internet]Evidence-based answers to questions that doctors commonly ask about COVID19[cited 2020 Apr 13]. Available from:https://deemagclinic.wordpress.com/2020/03/ 27/q-and-a/

5. Martini M, Gazzaniga V, Bragazzi NL, Barberis. The Spanish Influenza Pandemic: a lesson from history 100 years after 1918. J Prev Med Hyg. 2019;60(1):E64. DOI: $10.15167 / 2421$ 4248/jpmh2019.60.1.1205[cited 2020 Apr 11]. Available from: https://www.ncbi.nlm.nih.gov/pmc/articles/PMC647 7554/

6. The 1918 Influenza Pandemic: Responses[internet].[cited 2020 Apr 13]. Available from:

https://virus.stanford.edu/uda/fluresponse.html

7. who.int[internet]World Health Organization-Getting your workplace ready for COVID-19 [cited $2020 \mathrm{Apr}$ 13]. Available from: https://www.who.int/docs/default-

source/coronaviruse/advice-for-workplace-clean-1903-2020.pdf

8. cdc.gov[internet] ] Centre For Disease Control and Prevention-Prevent getting Sick [cited 2020 Apr 13 ] Available
[Lessons from 100 Years ago...] | Joseph B et al from:https://www.cdc.gov/coronavirus/2019ncov/prevent-getting-sick/social-distancing.html

9. economictimes.indiatimes.com[Internet]. The Economic Times:COVID-19: Hotel chains enforce precautionary measures, issue safety, hygiene advisories [cited 2020 Apr 13]. Available from: https://economictimes.indiatimes.com/industry/ser vices/hotels-/-restaurants/covid-19-hotel-chainsenforce-precautionary-measures-issue-safetyhygiene-advisories/articleshow

10. kpmg.in[internet].Potential effect of COVID-19 on the Indian Economy [cited 2020 Apr 13] Available from:https://home.kpmg/in/en/home/insights/2020 /03/the-business-implications-of-coronavirus.html

11. safeworkaustralia.gov.au.in[internet] Agriculture: Minimising the risk from COVID-19[cited 2020 Apr 13] Available from: https://www.safeworkaustralia.gov.au/covid-19information-workplaces/preparing-workplacescovid-19/agriculture-minimising-risk-covid-19

12. cdc.gov [Internet] Centre For Disease Control and Prevention - Preventing Spread of Disease on Commercial Aircraft: Guidance for Cabin Crew [cited 2020 Apr 13]. Available from: https://www.cdc.gov/quarantine/air/managing-sicktravelers/commercial-aircraft/infection-controlcabin-crew.html

13. betterwork.org[Internet]COVID 19: Fighting the crisis together in Bangladesh[cited 2020 Apr 13]Available From: https://betterwork.org/2020/03/31/covid-19fighting-the-crisis-together-in-bangladesh-

14. cdc.gov [Internet] Centre For Disease Control and Prevention - Talking with children about Coronavirus Disease 2019[cited 2020 Apr 13] Available

From:https://www.cdc.gov/coronavirus/2019ncov/daily-life-coping/talking-with-children.html

15. cdc.gov [Internet] Centre For Disease Control and Prevention - COVID-19: Guidance for School Settings[cited 2020 Apr 13] Available From: https://www.cdc.gov/coronavirus/2019-

ncov/community/schools-childcare/index.html

16. cdc.gov [Internet] Centre For Disease Control and Prevention - Interim Guidance for Administrators of $U$ . S . Institutions of Higher Education[cited $2020 \mathrm{Apr}$ 13] https://www.cdc.gov/coronavirus/2019ncov/community/colleges-universities/index.html

17. Erin P. Fraher, Patricia Pittman, Bianca K. Frogner, Joanne Spetz, Jean Moore, Dr.P.H., Angela J. Beck et al. Ensuring and Sustaining a Pandemic Workforce. New England Journal of Medicine. 2020; Apr:13.Available from:

https://www.nejm.org/doi/full/10.1056/ NEJMp2006376 DOI: 10.1056/NEJMp2006376 
INDIAN JOURNAL OF COMMUNITY HEALTH / VOL 32 / NO 02 (SPECIAL ISSUE) / APRIL 2020

[Lessons from 100 Years ago...] | Joseph B et al

18. John M Barry. Pandemics: Avoiding the mistakes of 1918. [Essay].Vol. 459, Nature. Nature Publishing Group.Available from: https://www.nature.com/articles/459324a

work[cited $2020 \mathrm{Apr}$ 13] Available From: https://www.ilo.org/global/about-the-

ilo/newsroom/news/WCMS_741358/lang-en/index.html

19. ilo.org[internet] International Labour Organization ILO Monitor 2nd Edition: COVID-19 and the world of 